\title{
IL-21R functions as an oncogenic factor and is regulated by the IncRNA MALAT1/miR-125a-3p axis in gastric cancer
}

\author{
LEI YAN $^{1 *}$, JING ZHANG $^{2 *}$, DONG GUO $^{1}$, JI MA $^{1}$, SHAO-FENG SHUI $^{1}$ and XIN-WEI HAN ${ }^{1}$ \\ ${ }^{1}$ Department of Interventional Radiology, The First Affiliated Hospital of Zhengzhou University, \\ Zhengzhou 450052; ${ }^{2}$ Department of Gastroenterology, Shanghai Jiao Tong University \\ Affiliated Sixth People's Hospital, Shanghai 200233, P.R. China
}

Received April 25, 2018; Accepted August 7, 2018

DOI: 10.3892/ijo.2018.4612

\begin{abstract}
Interleukin-21 receptor (IL-21R) is involved in the immunological regulation of immune cells and tumor progression in multiple malignancies. However, the potential molecular mechanisms through which non-coding RNAs (ncRNAs) modulate IL-21R signaling in gastric cancer (GC) remain elusive. In this study, the expression of IL-21R was detected by RT-qPCR and western blot analysis in GC cell lines. The association between IL-21R expression and clinicopathological characteristics and the prognosis of patients with GC was analyzed by immunohistochemistry and Kaplan-Meier plotter analysis. The biological functions of IL-21R were analyzed by a series of in vitro and in vivo experiments, and its regulation by ncRNAs was predicted by bioinformatics analysis and confirmed by luciferase assays and rescue experiments. As a result, the expression of IL-21R was found to be significantly increased in GC cell lines and tissues as compared with normal tissues, and was associated with tumor size and lymphatic metastasis, acting as an independent prognostic factor of poor survival and recurrence in patients with GC. The knockdown of IL-21R markedly suppressed GC cell proliferation and invasion, and IL-21R expression was further validated to be negatively regulated by miR-125a-3p (miR-125a). The overexpression of IL-21R reversed the tumor suppressive effects of miR-125a in vitro and in vivo. Moreover, lncRNA metastasis-associated lung adenocarcinoma transcript 1 (MALAT1) acted as a sponge of miR-125a to modulate the IL-21R signaling pathway in GC cells and represented a risk factor for survival and recurrence in patients with GC. Taken together, the findings of this study
\end{abstract}

Correspondence to: Professor Xin-Wei Han, Department of Interventional Radiology, the First Affiliated Hospital of Zhengzhou University, 1 East Jian She Road, Zhengzhou 450052, P.R. China E-mail: hanxinwei2018@163.com

*Contributed equally

Key words: interleukin-21 receptor, long non-coding RNA MALAT1, miR-125a-3p, gastric cancer, growth reveal an oncogenic role for IL-21R in gastric tumorigenesis and verify that its activation is partly due to the dysregulation of the IncRNA MALAT1/miR-125a axis. These findings may provide a potential prognostic marker for patients with GC.

\section{Introduction}

Gastric cancer (GC) as one of the most common malignant tumors and remains a leading cause of cancer-related mortality worldwide, and an estimated 1000,000 individuals are diagnosed with GC annually $(1,2)$. The activity imbalance between oncogenes and anti-oncogenes has been implicated in gastric carcinogenesis $(3,4)$. Accumulating evidence has indicated that the targeting of oncogenes or downstream genes associated with cancer progression may provide effective strategies for the intervention of carcinogenesis $(5,6)$.

Interleukin (IL)-21, identified as a member of the IL-2 family, is involved in biological activities in cancer and autoimmunity by binding to its receptor, IL-21R (7), which is highly expressed in hematological malignancies $(8,9)$ and enhances the aggressiveness of follicular lymphoma (10). IL-21/IL-21R axis results in the pathogenesis of leukemia and large cell lymphoma through activation of the JAK/STAT signaling pathway $(11,12)$, indicating that IL-21R may present a potential therapeutic target for cancer therapy. However, knowledge about the functions and regulatory mechanism of IL-21R in GC is limited.

Few genetic alterations and a low copy number gain for IL-21R suggest that post-transcriptional modulation may play a role in its upregulation in GC. In this study, using bioinformatic analysis, we found that IL-21R expression was mainly regulated by miR-125a (www.microrna.org), and it was listed in the top rank. MicroRNAs (miRNAs or miRs), a subgroup of small regulatory ncRNAs, which negatively modulate the protein-coding genes by binding to their 3 ' untranslated regions (3'UTRs) (13). The aberrant expression of miRNAs has been shown to be associated with various malignancies (14-16) and miRNAs can serve as non-invasive biomarkers for the prognosis of patients with GC $(17,18)$. miR-30a has been shown to suppress Th17 differentiation and demyelination by targeting IL-21R (19), and integrated miRNA-mRNA profiling has identified miR-583 as a negative regulator of IL2R $\gamma(20)$; however, the inhibition of miR-3940-5p has been shown to 
facilitate T-cell activity by targeting IL2R $\gamma$ (21). Increasing evidence documents the potential role of long non-coding RNAs (lncRNAs) as miRNA sponges in human cancer, and lncRNAs may emerge as important players in the regulation of miRNAs and their target genes $(22,23)$.

In the present study, we investigated the clinical significance of IL-21R expression in GC samples, and revealed the functions of IL-21R and its regulation by miR-125a and lncRNA metastasis-associated lung adenocarcinoma transcript 1 (MALAT1) in GC cells. The correlation of miR-125a with IL-21R or MALAT1 expression was analyzed in primary GC samples, and the association of MALAT1 expression with the poor survival of and recurrence in patients with GC was analyzed by Kaplan-Meier plotter analysis. We aimed to uncover the molecular mechanisms through which IL-21R upregulation contributes to gastric tumorigenesis and provide a potential therapeutic marker for clinical intervention.

\section{Materials and methods}

Cell culture. Human GC cell lines, including the undifferentiated HGC-27 cell line, the moderately differentiated SGC-7901 cell line, the poorly differentiated AGS and BGC-823 cell lines, the lowly differentiated MKN-45 cell line and the human gastric mucosa epithelial GES-1 cells were stored at the Laboratory of the First Affiliated Hospital of Zhengzhou University. The cells were cultured in a humidified incubator with $5 \% \mathrm{CO}_{2}$ at $37^{\circ} \mathrm{C}$ in RPMI-1640 medium or Dulbecco's modified Eagle's medium (DMEM; Nanjing KeyGen Biotech. Co. Ltd., Nanjing, China) containing $10 \%$ fetal bovine serum (FBS; Keygen).

Clinical samples and data. A tissue microarray (TMA) of gastric adenocarcinoma (GAC) (Chip lot no. HSTMAde180Sur-01; array no. I11-020-1) was provided by Outdo Biotech Co.,Ltd. (Shanghai, China). The TMA was prepared for immunohistochemical (IHC) analysis. Human GC tissues and the corresponding adjacent non-tumor tissues (ANTT) were obtained from the biopsy samples of 89 cases of GC admitted in the First Affiliated Hospital of Zhengzhou University (Zhengzhou, China) from January, 2007 to December, 2011. The baseline characteristics of the patients prior to neoadjuvant chemotherapy are summarized in Table I. This study was approved by Medical Ethics Committee of Zhengzhou University, and written informed consent was obtained from the patients prior to sample collection. Two pathologists respectively reviewed all the cases. In addition, 386 cases of GAC patients and 35 ANTT, as well as the relative expression level of IL-21R were downloaded from The Cancer Genome Atlas (TCGA)-GAC RNA sequencing database (https://genome-cancer.ucsc.edu). Other cohorts (GSE51105, GSE22377 and GSE15459) for the analysis of the prognostic value of lncRNA NEAT1 in GAC were downloaded from the Kaplan-Meier Plotter (http://kmplot.com/analysis/index. php? $\mathrm{p}=$ service $\&$ cancer $=$ gastric $)$.

Bioinformatics analysis. The analysis of genomic alterations (copy number, somatic mutation and mRNA upregulation) and the methylation level of IL-21R in GAC $(n=298)$ was conducted using a TCGA dataset and software cBioPortal (www.cbioportal.org). The miRNAs that may target the IL-21R gene were identified by using the prediction tool, microRNA.org (http://www.microrna.org/), according to the mirSVR and PhastCons scores, and the lncRNAs that may sponge miR-125a were screened out using starBase v2.0 (http://starbase.sysu.edu.cn/).

IHC analysis. IL-21R antibody (rabbit, polyclonal antibody, ab5980; Abcam, Cambridge, MA, USA) was used for the IHC detection of protein expression in the TMA. IL-21R antibody was used at a 1:200 dilution. Endogenous peroxidase was inhibited by incubation with freshly prepared $3 \%$ hydrogen peroxide with $0.1 \%$ sodium azide. Non-specific staining was blocked with $0.5 \%$ casein and $5 \%$ normal serum. The TMA samples were incubated with biotinylated antibodies and horseradish peroxidase. Staining was developed with diaminobenzidine substrate and the sections were counterstained with hematoxylin. PBS replaced IL-21R antibody in the negative controls and its expression was quantified as previously described (24).

Vector construction and transfection. Small interfering RNA (siRNA, $100 \mu \mathrm{M}$ ) targeting the IL-21R gene [siIL-21R sequence, CCTACACCTGCCACATGGATGTATT; or non-target negative control (NC) sequence, CCTCCACGTCACGTATAGTG ACATT] were provided by GenePharma (Shanghai, China). For MALAT1 overexpression, the full-length human MALAT1 cDNA was amplified using the following primers: Forward, 5'-GGCGGTACCATGAAACAATTTGGAGAAG-3' and reverse, 5'-GCGCTCGAGCTAAGTTTGTACATTTTGCC-3'; miR-125a mimic (forward, 5'-AGCTAAGCTTCTCTCTGTGT CTCTATTTCTGTCGTTT-3' and reverse, 5'-ACTGCTCGAG GTCAGGTTTCAGTTGGTGGTCAAATG-3') was provided by GenePharma, and lentivirus-mediated IL-21R was synthesized by Shanghai Genechem (Shanghai, China). The HGC-27 and MKN-45 cells were transfected with these vectors and were then incubated at $5 \% \mathrm{CO}_{2}$ at $37^{\circ} \mathrm{C}$. The medium was refreshed, and the cells were then cultured for a further $48 \mathrm{~h}$. The cell transfection efficiency was evaluated by reverse transcriptionquantitative PCR (RT-qPCR) and western blot analysis.

$R T-q P C R$. Total RNA was isolated from the GC cell lines using TRIzol reagent (Invitrogen, Carlsbad, CA, USA) according to the manufacturer's instructions. Complementary DNA (cDNA) was produced from the RNA using the PrimeScript ${ }^{\mathrm{TM}}$ Reverse Transcription kit (Takara, Tokyo, Japan) and its amplification was performed using the SYBR-Green Master Mix kit (Takara) according to the manufacturer's instructions on an ABI 7500 System (Applied Biosystems/Thermo Fisher Scientific, Waltham, MA, USA). The primers specific for IL-21R and miR-125a were designed and synthesized by Shanghai Sangon Biotech (Shanghai, China). Quantitative PCR for miR-125a-3p and IL-21R was performed using the SYBR-Green Master Mix kit and the specific primers as follows: Forward, 5'-TGA CACAGGTGAGGTTCTTG-3' and reverse, 5'-TATGGTTTTGA CGACTGTGTGAT-3'; IL-21R forward, 5'-CCCGACCTCG TCTGCTACA-3' and reverse, 5'-TGGTCTTGCCAGGTAAG GGT-3'; U6 forward, 5'-CAAATTCGTGAAGCGTTCCATA-3' and reverse, 5'-AGTGCAGGGTCCGAGGTATTC-3' and; GAPDH forward, 5'-CCTGTACGCCAACACAGTGC-3' and 
reverse, 5'-ATACTCCTGCTTGCTGATCC-3'. The PCR cycling conditions were as follows: $94^{\circ} \mathrm{C}$ for $30 \mathrm{sec}, 56^{\circ} \mathrm{C}$ for $30 \mathrm{sec}$, and $72^{\circ} \mathrm{C}$ for $90 \mathrm{sec}$, with 30 cycles, and a final extension at $72^{\circ} \mathrm{C}$ for $5 \mathrm{~min}$. Thus, the analysis of the relative gene expression data was conducted by using RT-qPCR and the $2^{-\Delta \Delta \mathrm{Cq}}$ method (25). miR-125a expression was normalized to the U6 expression level and GAPDH expression was used as an internal control for IL-21R. The experiments were performed 3 times.

Western blot analysis. The GC cells were harvested and proteins were extracted using lysis buffer $(100 \mathrm{mM}$ Tris- $\mathrm{HCl}$, $2 \%$ SDS, $1 \mathrm{mM}$ Mercaptoethanol and $25 \%$ glycerol). The cell extracts were boiled in loading buffer and equal amounts of cell extracts were separated on $15 \%$ SDS-PAGE gels. Separated protein bands were transferred into polyvinylidene fluoride (PVDF) membranes. The primary antibodies used were as follows: phosphorylated Janus kinase 2 (p-JAK2; rabbit monoclonal antibody, \#3776; Cell Signaling Technology, Danvers, MA, USA), phosphorylated signal transducer and activator of transcription 3 (p-STAT3; mouse monoclonal antibody, sc-8059; Santa Cruz Biotechnology, Santa Cruz, CA, USA) and anti-GAPDH (rabbit polyclonal antibody, ab153802, Abcam) and were diluted at a ratio of 1:1,000 according to the manufacturer's instructions and incubated with the membranes overnight at $4^{\circ} \mathrm{C}$. Horseradish peroxidase (HRP)-linked secondary antibodies (goat anti-mouse IgG, ab205719 and goat anti-Rabbit IgG, ab205718; Abcam) were added at a dilution ratio of 1:10,000, and incubated with the membranes at room temperature for $1 \mathrm{~h}$. The membranes were washed with PBS 3 times and the immunoreactive bands were visualized using ECL-PLUS (GE Healthcare, Piscataway, NJ, USA) according to the manufacturer's instructions.

Cell viability assay. GC cells $\left(2 \times 10^{3} /\right.$ well) were seeded in 96-well plates at $37^{\circ} \mathrm{C}, 5 \% \mathrm{CO}_{2}$. Following transfection with silL-21R or miR-125a mimic for $24,48,72,96$ and $120 \mathrm{~h}$, CCK-8 solution $(10 \mu \mathrm{l})$ was added to each well, followed by incubation for $2 \mathrm{~h}$. The optical densities at $492 \mathrm{~nm}$ were measured using a microplate reader (Molecular Devices, Sunnyvale, CA, USA).

Transwell invasion assay. Transwell 24 Well Permeable Supports (CLS3396) were purchased from Sigma-Aldrich (St. Louis, MO, USA), and its filters were coated with Matrigel on the upper surface of a polycarbonic membrane. Following incubation at $37^{\circ} \mathrm{C}$ for $30 \mathrm{~min}$, the Matrigel solidified and served as the extracellular matrix for analysis of tumor cell invasion. GC cells $\left(1 \times 10^{5}\right)$ in $100 \mu \mathrm{l}$ of serum-free DMEM were added to the upper compartment of the chamber. A total of $200 \mu \mathrm{l}$ conditioned medium was used as a source of chemoattractant, and placed in the bottom compartment of the chamber. Following $24 \mathrm{~h}$ of incubation at $37^{\circ} \mathrm{C}$ with $5 \% \mathrm{CO}_{2}$, the medium was removed from the upper chamber. The noninvaded cells on the upper side of the chamber were scraped off with a cotton swab. The cells that had migrated from the Matrigel into the pores of the inserted filter were fixed with $100 \%$ methanol, stained with hematoxylin $\left(15^{\circ} \mathrm{C}, 10 \mathrm{~min}\right)$, and mounted and dried at $80^{\circ} \mathrm{C}$ for $30 \mathrm{~min}$. The number of GC cells invading through the Matrigel was counted in 3 randomly selected visual fields from the central and peripheral portion of the filter using an inverted microscope (Olympus, Tokyo, Japan, x200 magnification). Each assay was repeated 3 times.

Dual-luciferase reporter assay. The GC cells were seeded into 24-well plates. Following $24 \mathrm{~h}$ of incubation, $1 \mathrm{mg}$ pmirGLO report vector (Promega Corp., Madison, WI, USA) carrying the wild-type 3'UTR or mutated 3'UTR of the miR-125a target was co-transfected with miR-125a or miR-NC into the GC cells. At $48 \mathrm{~h}$ following transfection, Firefly and Renilla luciferase activities were examined using a Dual-luciferase Reporter System (Promega). pmirGLO report vector was used as a positive control.

In vivo tumor xenograft experiments. Six-week-old nude mice (BALB/c-nu) $(\mathrm{n}=15$, female) were bred at the Laboratory Animal facility of Zhengzhou University, and were housed individually in microisolator ventilated cages (temperature, $26-28^{\circ} \mathrm{C}$; 40-60\% humidity and ventilation for 10-15 times/h) with free access to water and food. All experimental procedures were performed according to the regulations and internal biosafety and bioethics guidelines and the use of animals was approved by the Ethics Review Commission of Zhengzhou University. For the localized model, $2 \times 10^{7}$ GC MKN-45 cells stably transfected with IL-21R, miR-125a and empty vector were injected subcutaneously into the right flanks of the 6-week old female BALB/c nude mice, which were supplied by Shanghai SLAC Laboratory Animal Co. Mice bearing tumors approximately $0.5 \mathrm{~cm}$ in diameter were randomized into the miR-NC + Lv-NC, miR-125a + Lv-IL-21R and miR-125a + Lv-NC groups ( $n=5$ in each group). The tumors were measured every 3 days and the tumor volume was calculated according to the following formula: Length $\mathrm{x}$ width ${ }^{2} / 2$.

Statistical analysis. Data are presented as the means \pm SEM. The Kruskal-Wallis H test, Mann Whitney U test with Bonferroni's correction and the Chi-square test were applied to analyze the differential expression of IL-21R in GC and adjacent normal tissues. Pearson's correlation coefficient analysis was used to observe the correlations between IL-21R or MALAT1 expression and miR-125a in GC tissues. Gene expression, cell proliferation and invasion were calculated using a Student's t-test or one-way analysis of variance (ANOVA) between groups. For the parental and control groups, the LSD method of multiple comparisons was used when the probability for ANOVA was statistically significant. Survival and recurrence curves were analyzed with the Kaplan-Meier method (www.kmplot.com) and log-rank test. Differences were considered statistically significant at $\mathrm{P}<0.05$.

\section{Results}

Expression of IL-21R is upregulated in GC samples. IL-21R has been reported to be upregulated in diffuse large B-cell lymphoma (DLBCL) and to be associated with an unfavorable prognosis in patients with DLBCL (10). However, to date, at least to the best of our knowledge, little is known about the expression of IL-21R in human GC. In this study, the expression of IL-21R was examined by IHC analysis, and the results revealed that its expression level was increased in the 89 cases of GC as compared with the ANTT (65.17 vs. $47.19 \%$, 
$\mathrm{P}=0.015$ ) (Fig. 1A). The mRNA level of IL-21R was then validated by the datamining of the RNA sequencing data from GAC publicly available at The Cancer Genome Atlas database (TCGA), which indicated that IL-21R expression was markedly increased in the total GAC samples $(n=386)$ or pairmatched tissues $(n=32)$ as compared with the adjacent normal tissues (Fig. 1B). Consistently, IL-21R expression was upregulated in the GC cell lines as compared with the immortalized GES-1 cells (Fig. 1C). To further explore the reasons for the upregulation of IL-21R in GC, we examined the genomic alterations of IL-21R in the TCGA cohort by cBioPortal (www.cbioportal.org) (26), including copy number, somatic mutation and mRNA upregulation, indicating that only $6 \%$ of cases $(18 / 298)$ had the genetic alterations for IL-21R, of which its mRNA upregulation accounted for $2.7 \%$ of the cases. Moreover, IL-21R mRNA upregulation could not be explained by the copy number alterations in the GC samples (Fig. 1D).

$I L-21 R$ overexpression is associated with a poor prognosis of patients with GC. According to the results presented in Fig. 1A, the samples were divided according to the IL-21R expression level into the IL-21R high expression (intermediate/strong, $\mathrm{n}=30$ ) and low expression (negative/low, $\mathrm{n}=59$ ) groups. As indicated in Table I, IL-21R high expression was positively associated with tumor size $(\mathrm{P}=0.015)$ and lymphatic metastasis $(\mathrm{P}=0.031)$ in the patients with $\mathrm{GC}$, but had no association with other clinical factors (each $\mathrm{P}>0.05$ ). Kaplan-Meier analysis revealed that the patients with GC with a high IL-21R expression had a shorter survival time and a higher recurrence rate compared with those with a low IL-21R expression (Fig. 1E). To further confirm this result, Kaplan Meier plotter analysis (www.kmplot.com) (27) demonstrated that a high IL-21R expression was associated with a poor survival and recurrence in patients with GC (Fig. 1F).

Knockdown of IL-21R suppresses cell proliferation and invasion. As IL-21R was found to be expressed abundantly in the MKN-45 and HGC-27 cell lines, we performed siRNA-mediated knockdown experiments to investigate its function in these two cell lines. Following transfection with siIL-21R or $\mathrm{NC}$, both the mRNA and protein levels of IL-21R were significantly decreased in these cells (Fig. 2A). The knockdown of IL-21R reduced the cell proliferative activities, as shown by CCK-8 assay (Fig. 2B). In addition, the cell invasive ability was evidently weakened by siIL-21R transfection as compared with the NC group (Fig. 2C and D).

$I L-21 R$ is a direct target of $m i R-125 a$ in $G C$. According to the binding sites with the IL-21R 3'UTR, miRNAs were identified by microRNA.org (http://www.microrna.org/) with the mirSVR and PhastCons score. We found that miR-125a-3p (miR-125a) was ranked at the top of the miRNA list and had the potential to bind with IL-21R 3'UTR. Given the negative correlation of miRNAs with their target genes, we used the TCGA cohort to analyze the correlation of IL-21R with miR-125a expression in paired GC samples, indicating that miR-125a expression was downregulated (Fig. 3A) and exhibited a negative correlation with IL-21R expression in the GC samples (Fig. 3B). To confirm whether IL-21R is a direct target of miR-125a, we performed a luciferase assay. The binding site of miR-125a with IL-21R 3'UTR is shown in Fig. 3C. Transfection with miR-125a mimic inhibited the luciferase activity of the wildtype (Wt) IL-21R 3'UTR, but had no effect on the mutant (Mut) sequence of the binding site (Fig. 3D). Additionally, both the mRNA and protein expression levels of IL-21R were decreased in the HGC-27 and MKN-45 cells following transfection with miR-125a mimic (Fig. 3E). These results suggested miR-125a regulates IL-21R expression by targeting its 3'UTR.

$I L-21 R$ overexpression reverses the tumor suppressive effects of $m i R-125 a$. Rescue experiments were further conducted to determine whether IL-21R is a functional target of miR-125a in GC cells. Following co-transfection with Lv-IL-21R and miR-125a mimic for $72 \mathrm{~h}$, a CCK-8 proliferation assay revealed that the overexpression of IL-21R increased the cell proliferative activity and partly attenuated the anti-proliferative effects of miR-125a on the HGC-27 and MKN-45 cell lines (Fig. 4A). In addition, the enforced expression of IL-21R enhanced the cell invasive potential and partly alleviated the inhibitory effects induced by miR-125a in the HGC-27 and MKN-45 cell lines (Fig. 4B-D). Moreover, our in vivo experiments illustrated that the overexpression of IL-21R partly abolished the antitumor effects of miR-125a (Fig. 4E and F), indicating that IL-21R was a target of miR-125a in GC.

lncRNA MALAT1 functions as an endogenous sponge of $m i R$-125a.FormiR-125a-3p, ata very highstringency, $31 \mathrm{ncRNAs}$ including MALAT1, LINC00657 and CTC-444N24.11 were identified to have a complementary sequence of miR-125a-3p using starBase v2.0 (http://starbase.sysu.edu.cn/) (Fig. 5A), of which MALAT1 as a star lncRNA, has been implicated in the tumorigenesis and progression of multiple malignancies, including GC (28-30). Thus, in this study, we first analyzed MALAT1 expression and its correlation with miR-125a, and found that MALAT1 expression was upregulated (Fig. 5B) and negatively correlated with miR-125a expression in the GC samples (Fig. 5C). To verify whether MALAT1 can bind to miR-125a, we conducted a luciferase gene reporter assay. The binding site of MALAT1 with miR-125a is shown in Fig. 5D. Dual-luciferase assay demonstrated a marked decrease in the luciferase activities following co-transfection of the cells with miR-125a mimics and Wt-MALAT1 expression vector, but not with the Mut-MALAT1 vector (Fig. 5E). The restored expression of MALAT1 decreased miR-125a expression (Fig. 5F), whereas it increased IL-21R expression (Fig. 5G). Transfection with miR-125a mimic not only inhibited the activities of the IL-21R/JAK2/STAT3 pathway, but also partly attenuated the increased activities of this pathway induced by MALAT1, as indicated by western blot analysis (Fig. 5H). The results of CCK-8 assay revealed that the increased proliferative activities induced by MALAT1 were reduced by miR-125a in the GC cells (Fig. 5I). These results suggest that lncRNA MALAT1 may act as an endogenous sponge of miR-125a to regulate IL-21R signaling in GC cells.

IncRNA MALAT1 is associated with a poor survival of and recurrence in patients with $G C$. The expression of lncRNA MALAT1 has been shown to be upregulated in $\operatorname{GC}(29,31)$. Thus, in this study, we investigated whether it was associated with the survival of and recurrence in patients with GC. Using 
A

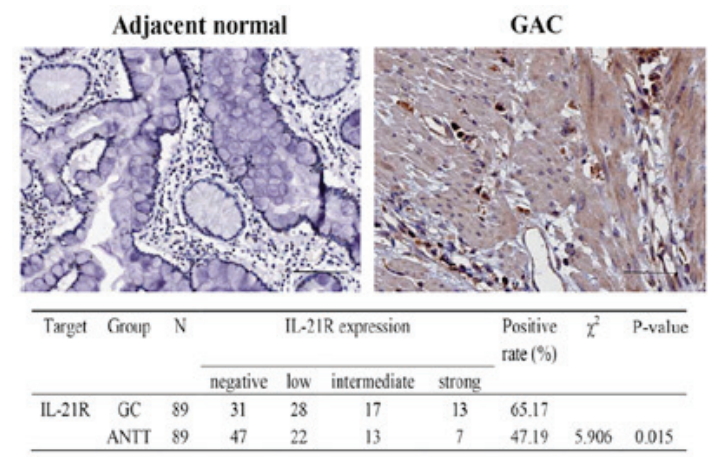

B
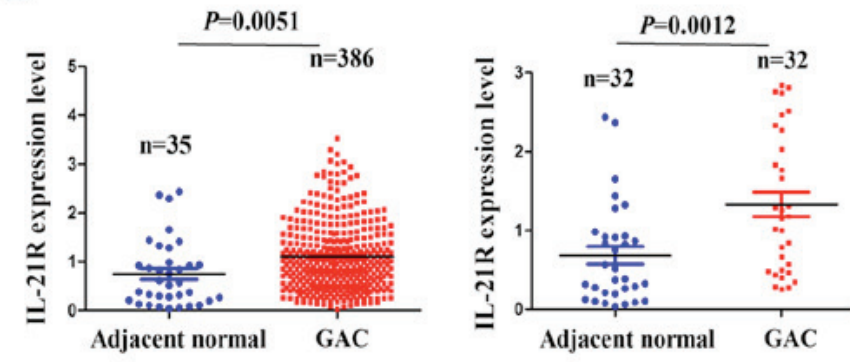

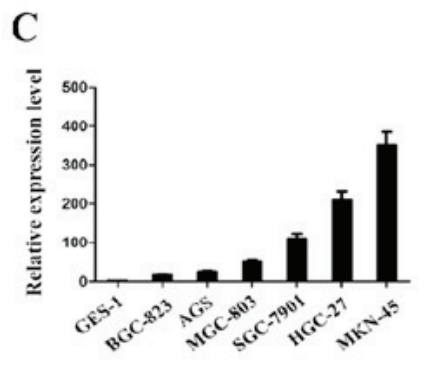

D
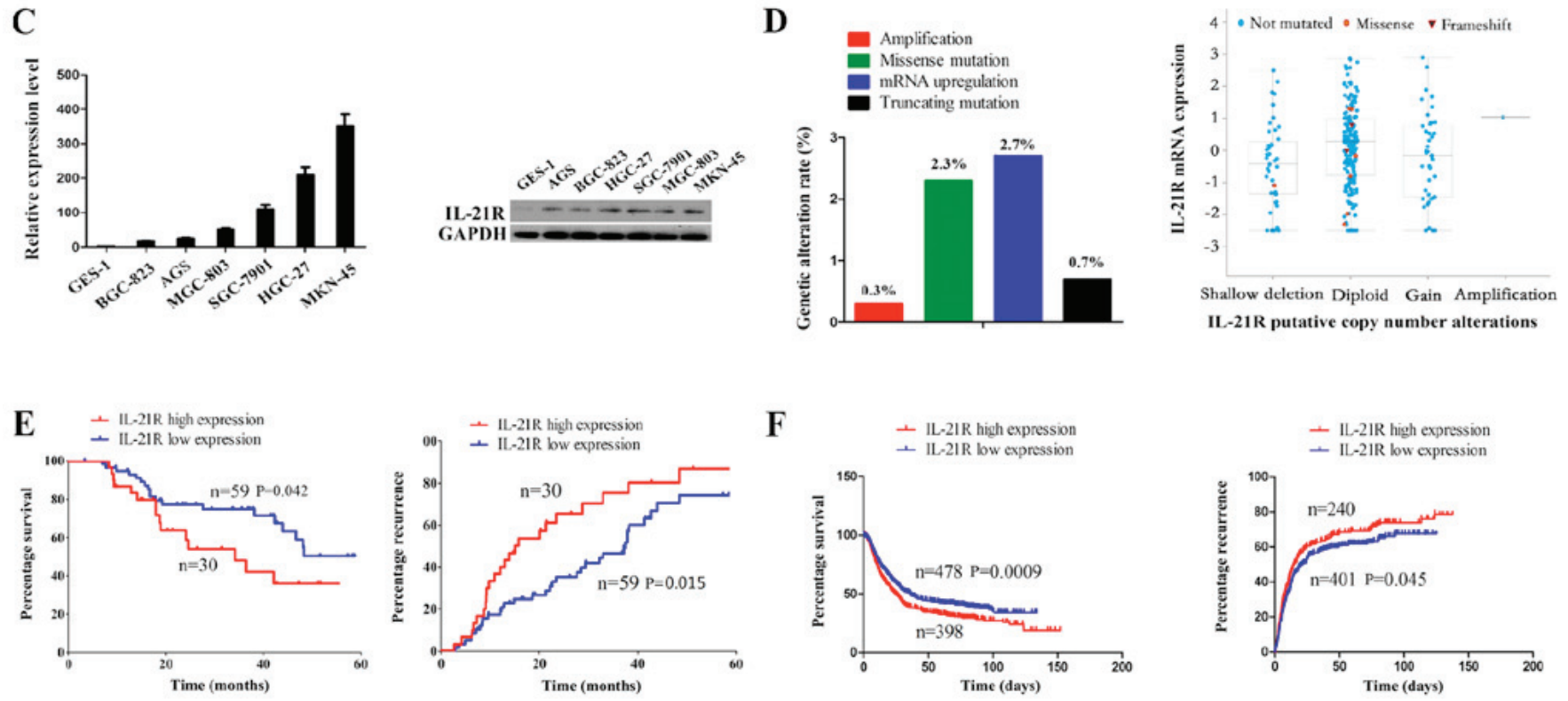

Figure 1. The expression of IL-21R is upregulated in gastric cancer (GC) samples. (A) Immunohistochemical (IHC) analysis of the protein expression of IL-21R in gastric adenocarcinoma (GAC) samples and adjacent normal samples ( $\mathrm{n}=89$; magnification, $\mathrm{x} 400)$. (B) TCGA cohort analysis of the mRNA expression level of IL-21R in unpaired and paired GAC samples. (C) RT-qPCR and western blot analysis of the expression level of IL-21R in GC cell lines and GES-1 normal cells. (D) The genetic and copy number alterations of IL-21R in GC. Proportion of genetic alterations of IL-21R, and the association between IL-21R expression level and its putative copy number alterations are shown. (E) Kaplan-Meier analysis of the association of IL-21R expression with poor survival and recurrence in patients with GC. (F) TCGA cohort analysis of the association of IL-21R expression with overall survival and recurrence in patients with GC.
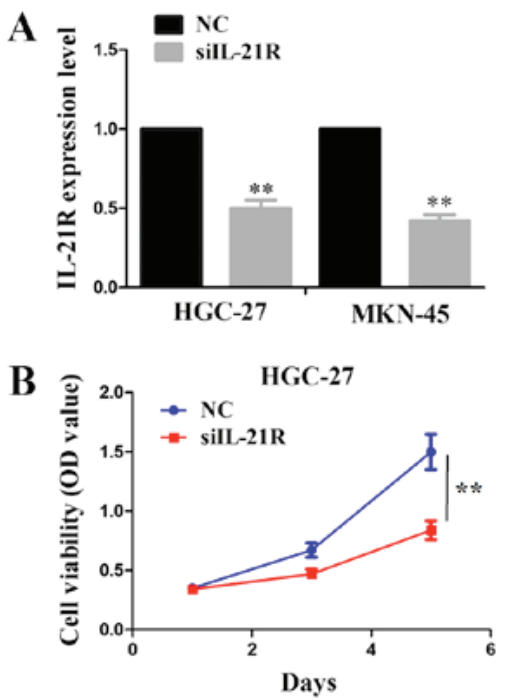
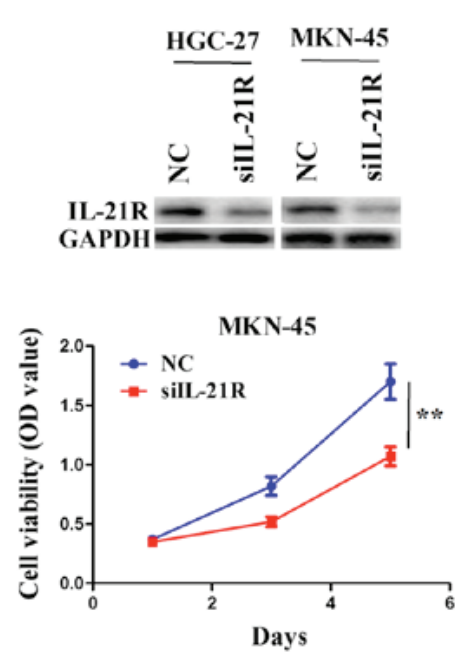

C

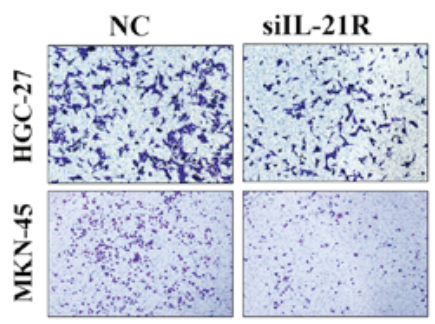

D

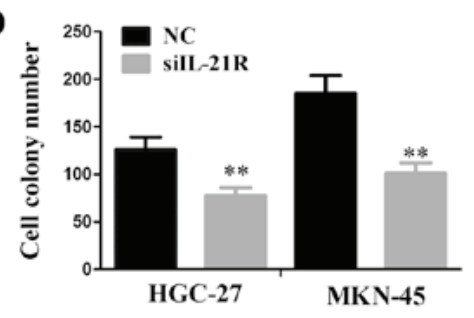

Figure 2. Knockdown of IL-21R suppresses cell proliferation and invasion. (A) RT-qPCR and western blot analysis of the knockdown efficiency following transfection with siIL-21R for $48 \mathrm{~h}$ in the HGC-27 and MKN-45 cell lines. (B) CCK-8 assay was used to detect the effects of IL-21R knockdown on cell proliferative activities. (C and D) Transwell invasion assay was conducted to assess the effects of IL-2R knockdown on the invasive potential of gastric cancer (GC) cells. ${ }^{* * *} \mathrm{P}<0.01$ vs. NC. 
A

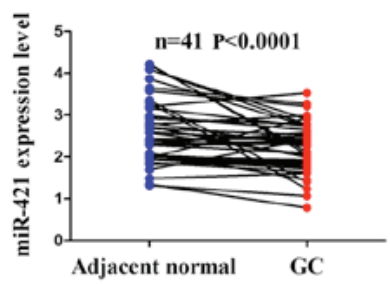

D

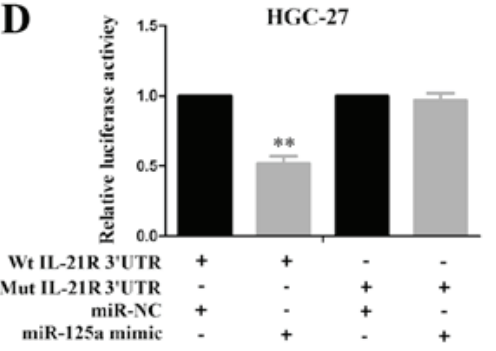

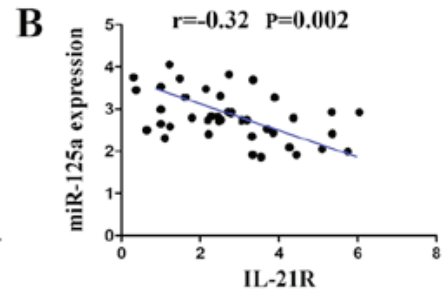

C
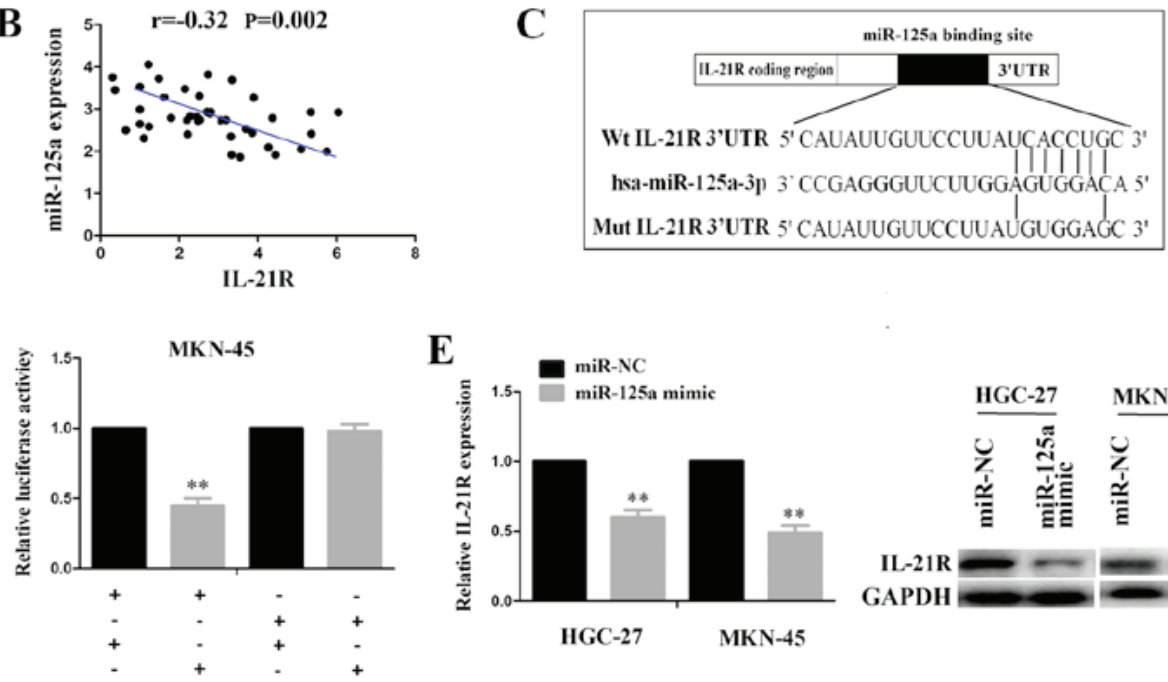

$\mathbf{E}$

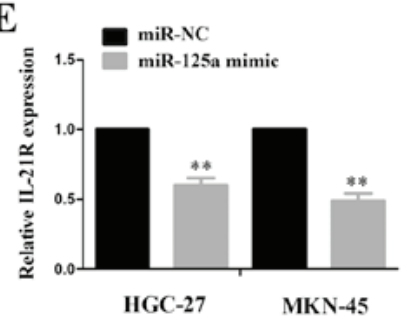

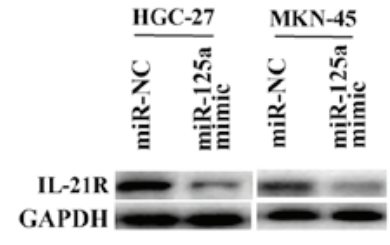

Figure 3. IL-21R is a direct target of miR-125a in gastric cancer (GC). (A) TCGA cohort analysis of the expression level of miR-125a between gastric adenocarcinoma (GAC) and pair-matched normal tissues. (B) TCGA cohort analysis of the correlation of IL-21R expression with miR-125a in 41 gastric adenocarcinoma (GAC) samples. (C) Schematic representation of the binding site of miR-125a with IL-21R 3'UTR. (D) The luciferase activities of wild-type (Wt) IL-21R 3'UTR or mutant (Mut) type IL-21R 3'UTR following co-transfection with miR-125a mimic and wt-IL-21R 3'UTR vector or mut-IL-21R 3'UTR vector in the HGC-27 and MKN-45 cell lines. (E) RT-qPCR and western blot analysis of the expression level of IL-21R in GC cells following transfection with miR-125a mimic. ${ }^{* *} \mathrm{P}<0.01$ vs. miR-NC.

Table I. Association of IL-21R expression with clinicopathological factors of patients with gastric cancer.

\begin{tabular}{|c|c|c|c|c|}
\hline \multirow[b]{2}{*}{ Parameters } & \multirow{2}{*}{$\begin{array}{c}\text { Patients } \\
\text { n (\%) } \\
89(100)\end{array}$} & \multicolumn{2}{|c|}{ IL-21R expression } & \multirow[b]{2}{*}{ P-value } \\
\hline & & $\begin{array}{l}\text { Low }(\%) \\
59(66.3)\end{array}$ & $\begin{array}{l}\text { High (\%) } \\
30(33.7)\end{array}$ & \\
\hline \multicolumn{5}{|l|}{ Age (years) } \\
\hline$\geq 60$ & 29 & $16(55.2)$ & $13(44.8)$ & \\
\hline$<60$ & 60 & $43(71.7)$ & $17(28.3)$ & 0.125 \\
\hline \multicolumn{5}{|l|}{ Sex } \\
\hline Female & 20 & $11(55.0)$ & $9(45.0)$ & \\
\hline Male & 69 & $48(69.6)$ & $21(30.4)$ & 0.228 \\
\hline \multicolumn{5}{|l|}{ Tumor size $(\mathrm{cm})$} \\
\hline$\geq 3.5$ & 17 & $7(41.2)$ & $10(58.8)$ & \\
\hline$<3.5$ & 72 & $52(72.2)$ & $20(27,8)$ & 0.015 \\
\hline \multicolumn{5}{|l|}{ TNM stage } \\
\hline $\mathrm{I} / \mathrm{II}$ & 32 & $18(56.3)$ & $14(43.7)$ & \\
\hline III/IV & 57 & $41(71.9)$ & $16(28.1)$ & 0.135 \\
\hline \multicolumn{5}{|l|}{ Differentiation } \\
\hline Well/moderate & 27 & $16(59.3)$ & $11(40.7)$ & \\
\hline Poor & 62 & $43(69.4)$ & 19 (30.6) & 0.357 \\
\hline \multicolumn{5}{|l|}{$\mathrm{T}$ classification } \\
\hline $\mathrm{T} 1 / \mathrm{T} 2$ & 19 & $13(68.4)$ & $6(31.6)$ & \\
\hline $\mathrm{T} 3 / \mathrm{T} 4$ & 70 & $46(65.7)$ & $24(34.3)$ & 0.826 \\
\hline \multicolumn{5}{|l|}{$\mathrm{N}$ classification } \\
\hline Negative & 66 & $48(72.7)$ & $18(27.3)$ & \\
\hline Positive & 23 & $11(47.8)$ & $12(52.2)$ & 0.031 \\
\hline
\end{tabular}

the online Kaplan Meier plotter tools (www.kmplot.com) (27), we found that in the cohorts in the GSE51105, GSE22377 and GSE15459 databases, the patient with GC with a high MALAT1 expression exhibited a lower survival rate compared with those with a low MALAT1 expression (Fig. 6A); In the cohorts in the GSE22377 and GSE15459 databases, it was found that the patients with GC with a high MALAT1 expression displayed a higher recurrence rate compared with those with a low MALAT1 expression (Fig. 6B). These data thus indicated that IncRNA MALAT1 may represent a risk factor for survival and recurrence in patients with GC. According to all the results obtained in vitro and in vivo, we found that lncRNA MALAT1 may act as a sponge of miR-125a to regulate IL-21R signaling, leading to gastric tumorigenicity (Fig. 7).

\section{Discussion}

IL-21 mainly originates from activated $\mathrm{CD}^{+} \mathrm{T}$ cells and natural killer (NK) T cells and exerts its function by interacting with IL-21R, which is expressed in lymphoid tissues, as well as in epithelial cells (32). Recent studies have demonstrated that the ectopic expression of IL-21R is found in hematological malignancies, such as DLBCL (10), adult T-cell leukemia (33) and chronic lymphocytic leukemia (34). However, little knowledge is available regarding the IL-21R expression level in other epithelial tumors, particularly in GC, at least to the best of our knowledge. In this study, we found that IL-21R exhibited an increased expression in GC. The use of the TCGA cohort further verified this result in 386 cases of GAC samples. Consistent with previous reports $(10,33,34)$, a high IL-21R expression was found to be associated with tumor size, lymphatic metastasis, poor survival and recurrence, acting as an independent prognosis factor for the survival of and recurrence in patients with GC. The results of this study indicated that IL-21R may represent a potential biomarker for GC.

Functionally, IL21R, expressed by bone marrow $\mathrm{CD}_{14}{ }^{+}$ cells, accelerates osteoclast formation in multiple myeloma 
A

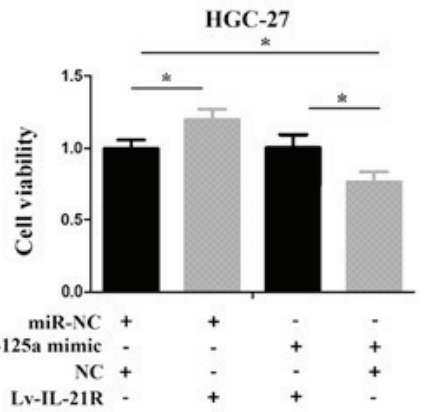

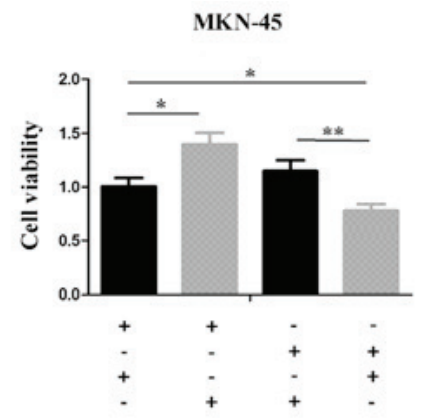

B

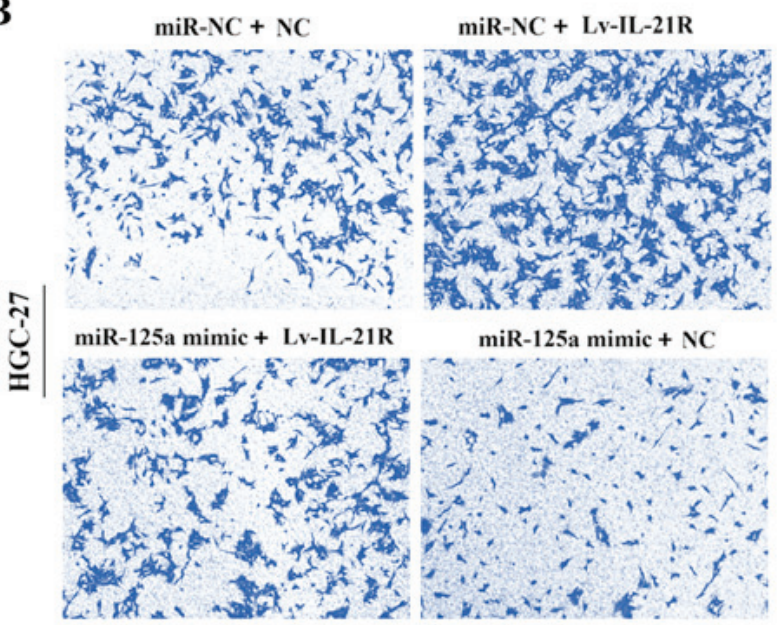

D
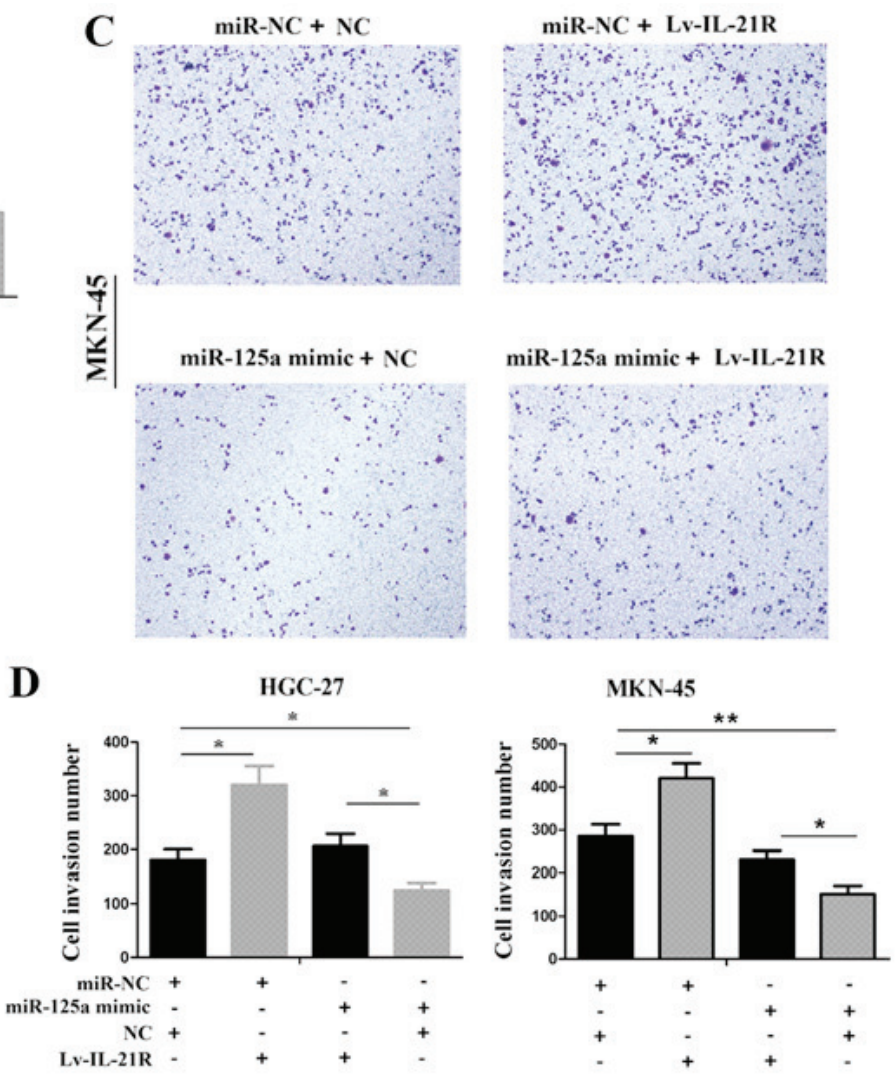

$\mathbf{E}$
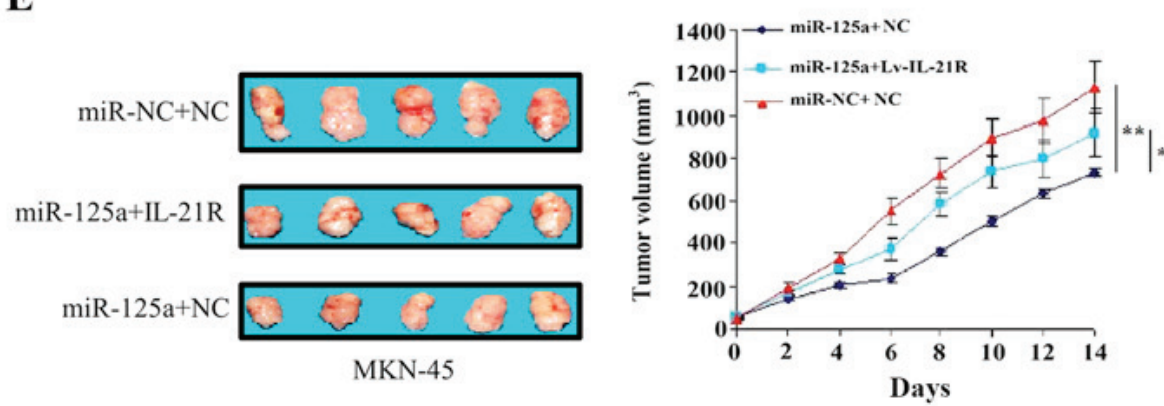

Figure 4. IL-21R overexpression reverses the tumor suppressive effects of miR-34a on gastric cancer (GC) cells. (A) Cell proliferative activities were evaluated by CCK-8 assay in the HGC-27 and MKN-45 cell lines following transfection with Lv-IL-21R and/or miR-125a mimic. (B-D) Cell invasive potential was assessed by Transwell invasion assay in the HGC-27 and MKN-45 cell lines following transfection with Lv-IL-21R and/or miR-125a mimic. (E and F) In vivo animal experiments for the validation of the effects of IL-21R overexpression on the antitumor effects of miR-125a. ${ }^{*} \mathrm{P}<0.05$ and ${ }^{* *} \mathrm{P}<0.01$. patients (33), participates in the mediation of pro-apoptotic signals in CLL B cells (35) and matrix metalloproteinase signaling in breast cancer, and promotes tumor proliferation, migration and invasion (36). In this study, we also found that the knockdown of IL-21R suppressed GC cell proliferation and invasion. These results indicate that IL-21R may play an oncogenic role in GC cells.

To further explore the mechanisms of action of IL-21R in GC, we investigated its genetic and copy number alterations in $\mathrm{GC}$ and found these factors could not comprehensively explain the reasons for IL-21R upregulation in GC. Thus, we focused on its post-transcriptional regulation, such as miRNAs. By bioinformatics analysis, we identified IL-21R as a direct target of miR-125a, and IL-21R overexpression partly alleviated the tumor suppressive effects of miR-125a in GC in vitro and in vivo. Other studies have demonstrated that miR-125a functions as a tumor suppressive factor in various types of cancer (37-39). These data suggested the upregulation of IL-21R was partly due to the downregulation of miR-125a in GC.

It has been recently demonstrated that lncRNAs function as miRNAs sponges and inhibit their activities and functions (40). Accumulating data have indicated that lncRNA MALAT1 promotes cell proliferation, migration and metastasis, and decreases cell apoptosis by sponging multiple miRNAs in various malignancies, such as miR-143-3p and miR-204 in hepatocellular carcinoma $(41,42)$, miR-101 in glioma (43), and miR-429 in renal cell carcinoma (44). Of note, in this study, we also identified MALAT1 as a negative regulator of miR-125a-3p in GC samples, and confirmed that MALAT1 could bind to miR-125a, thereby inhibiting its activity and increasing IL-21R expression. Rescue experiments demonstrated that miR-125a mimic suppressed the activation of the IL-21R/JAK2/STAT3 signaling pathway and partly 

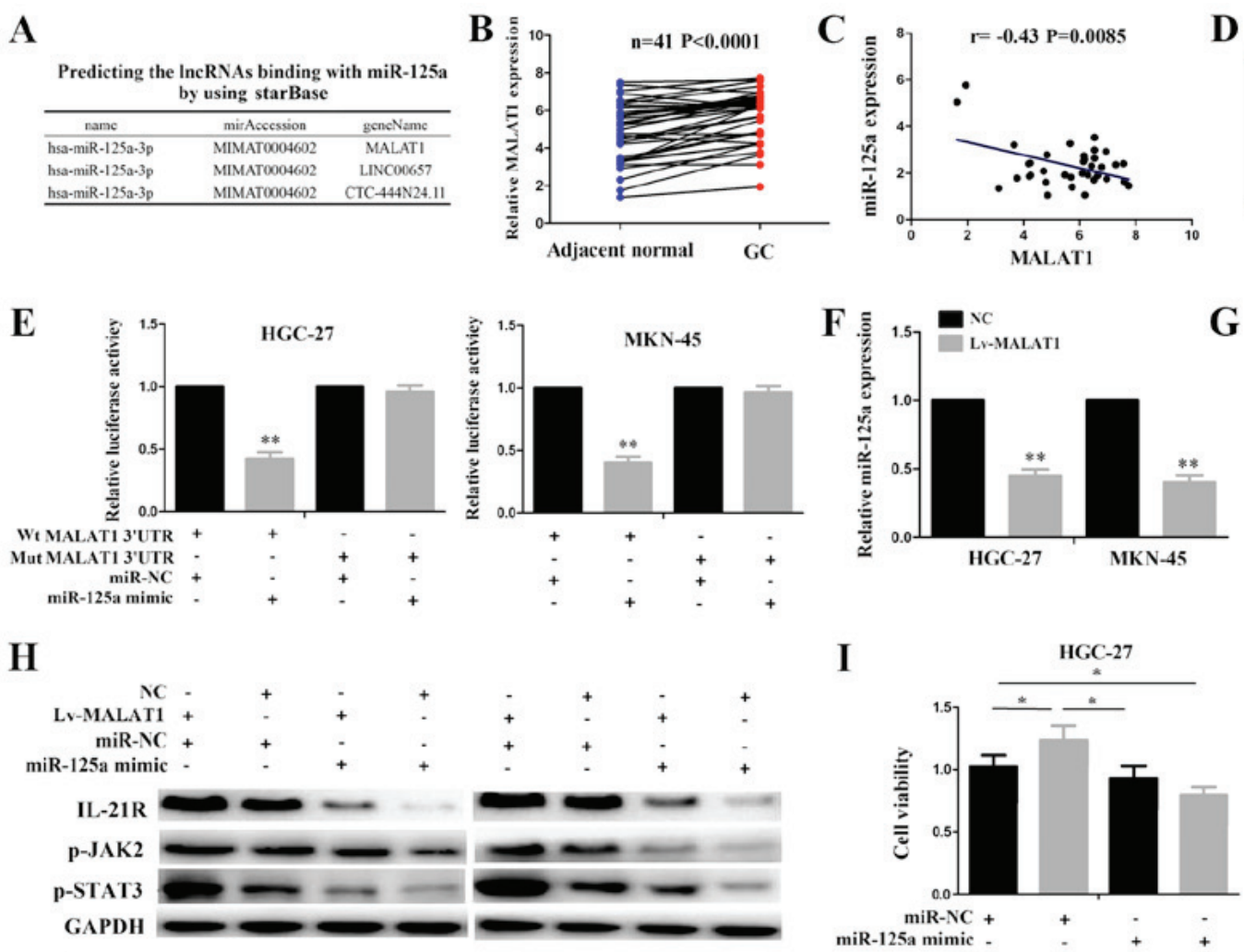
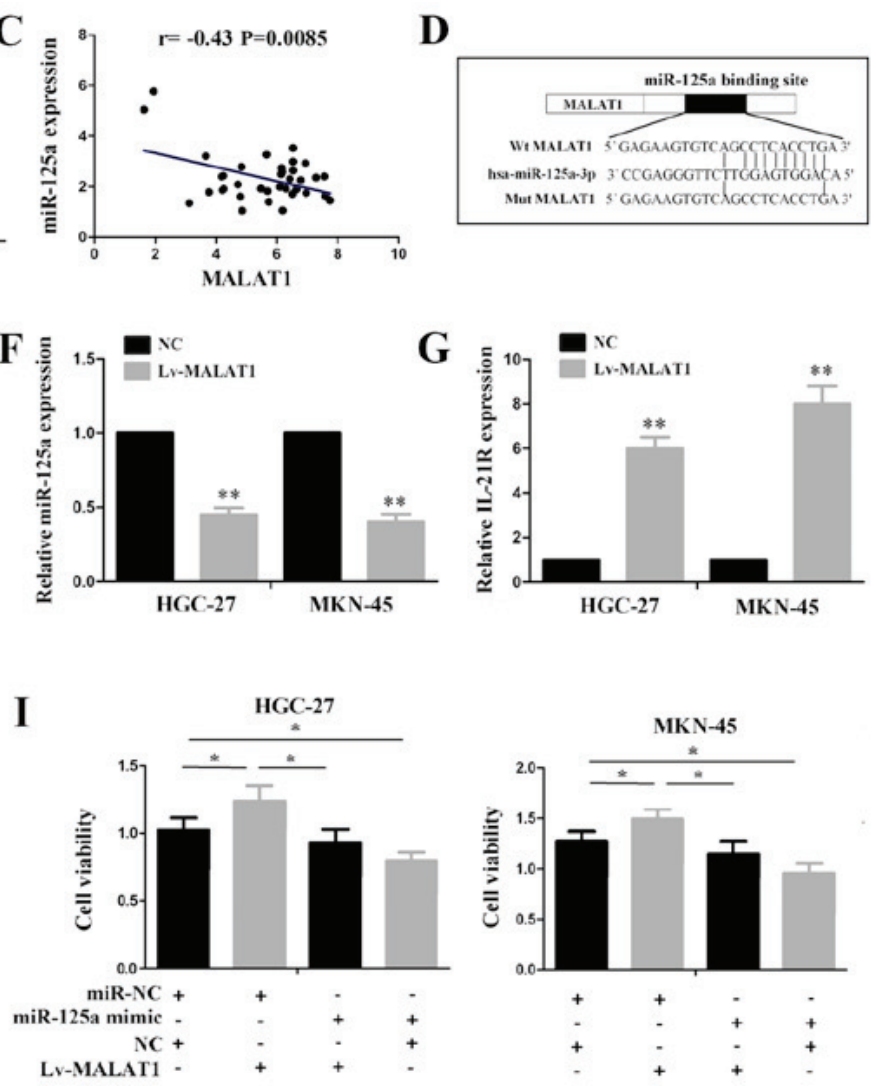

Figure 5. lncRNA MALAT1 functions as an endogenous sponge of miR-125a in gastric cancer (GC). (A) Bioinformatics identification of the lncRNAs that can bind to miR-125a-3p. (B) TCGA cohort analysis of the expression level of IncRNA MALAT1 in 41 GAC samples. (C) TCGA cohort analysis of the correlation of MALAT1 expression with miR-125a in 41 GAC samples. (D) Schematic representation of the binding site of miR-125a with MALAT1. (E) The luciferase activities of wild-type (Wt) MALAT1 or mutant (Mut) type MALAT1 following co-transfection with miR-125a mimic and wt-MALAT1 vector or mut-MALAT1 vector in HGC-27 and MKN-45 cell lines. (F and G) qRT-PCR analysis of the expression level of miR-125a and IL-21R in GC cells following transfection with Lv-MALAT1. (H) Western blot analysis of the transduction activity of the IL-21R pathway in GC cells following transfection with Lv-MALAT1 and/or miR-125a mimic. (I) CCK-8 assay detection of the proliferative activities of GC cells following transfection with Lv-MALAT1 and/or miR-125a mimic. ${ }^{*} \mathrm{P}<0.05$ and ${ }^{* *} \mathrm{P}<0.01$.
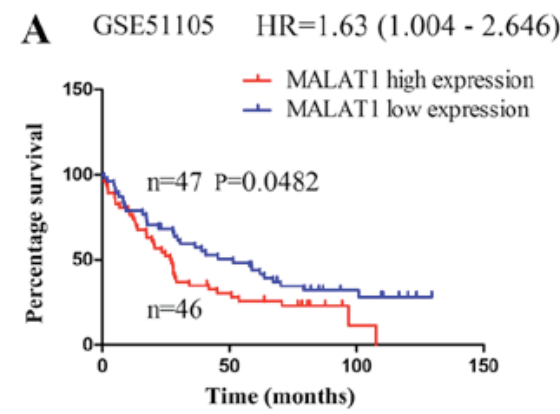

B GSE22377 HR=2.934 (1.411-6.103)

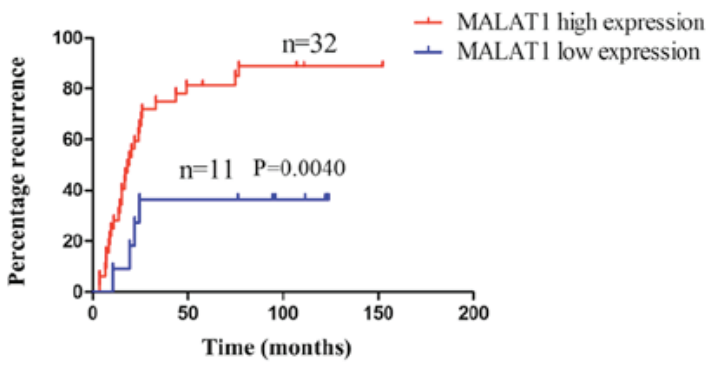

GSE22377 HR=2.757 (1.290 - 5.896)

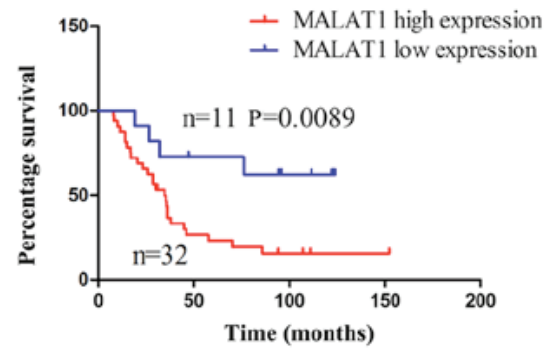

GSE15459 HR=1.905 (1.262 - 2.876)

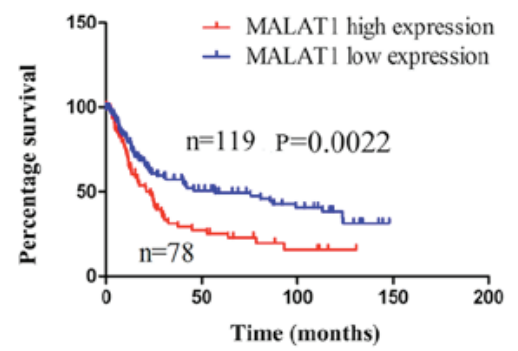

GSE15459 HR=1.663 $(1.129-2.451)$

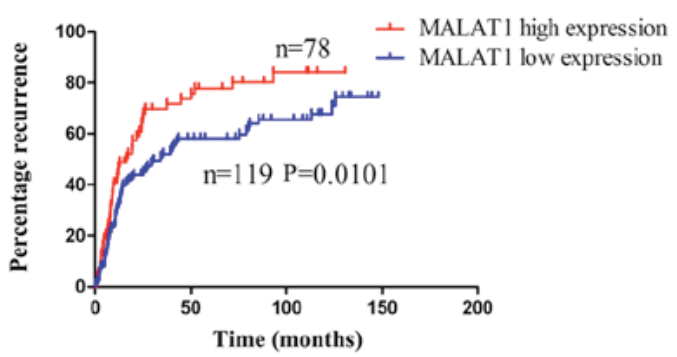

Figure 6. IncRNA MALAT1 is associated with poor survival and recurrence in gastric cancer (GC). (A) The association of lncRNA MALAT1 expression with overall survival of GC in the cohorts from the GSE51105, GSE22377 and GSE15459 databases using the online Kaplan Meier plotter tool. (B) The association of lncRNA MALAT1 expression with the recurrence of GC in the cohorts from the GSE22377 and GSE15459 databases using the online Kaplan Meier plotter tool. 

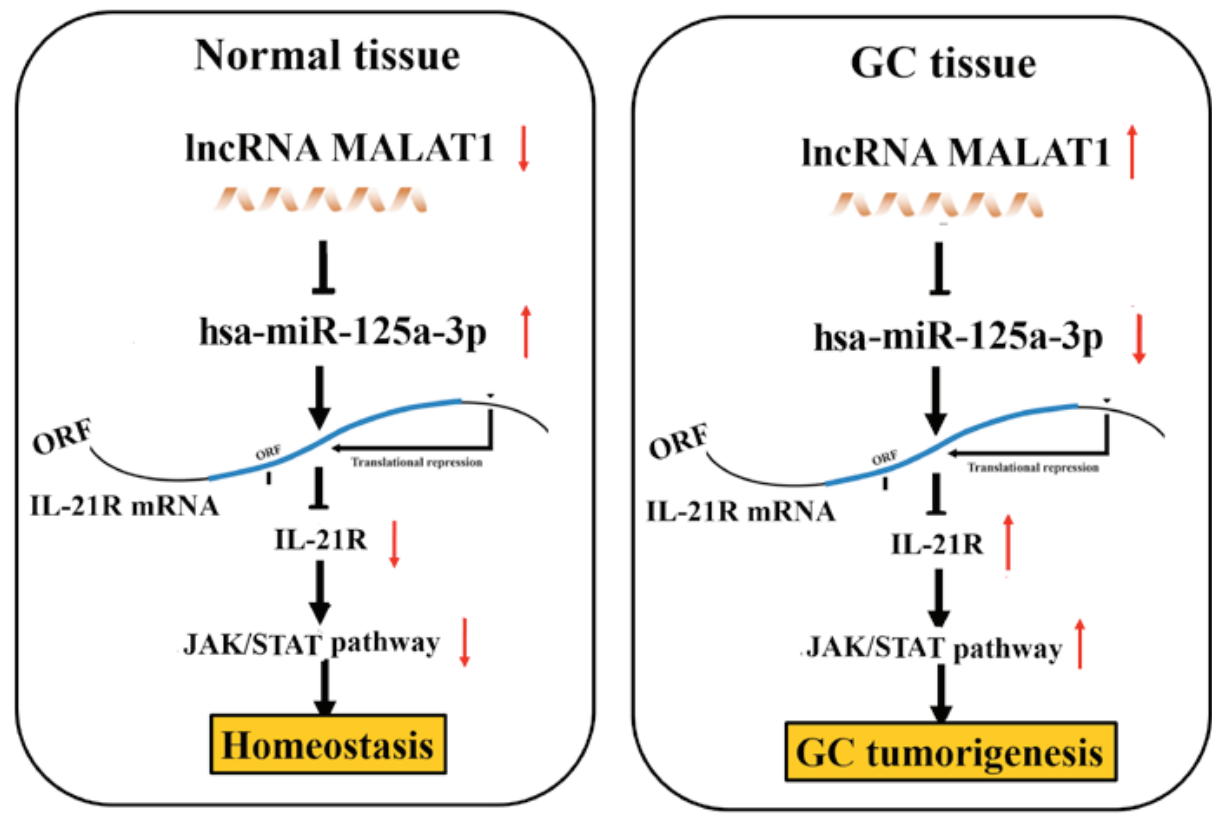

Figure 7. Schematic representation of the proposed mechanisms of action of the lncRNA MALAT1/miR-125a/IL-21R axis in gastric cancer (GC) cells lncRNA MALAT1 functions as a sponge of miR-125a to regulate IL-21R/JAK/STAT signaling, thus leading to gastric tumorigenicity.

reversed the promoting effects of MALAT1 on this signaling pathway and on the proliferation of GC cells. These data suggest lncRNA MALAT1 functions as a sponge of miR-125a to regulate IL-21R signaling in GC cells. The findings of this study further documented that MALAT1 was a biomarker for GC metastasis and represented a risk factor for the survival and recurrence of GC.

In conclusion, the upregulation of IL-21R in GC was associated with tumor size and lymphatic metastasis and acted as an independent prognostic factor of a poor survival and recurrence in GC. IL-21R functioned as an oncogenic factor and alleviated the suppressive effects of miR-125a in GC cells. 1ncRNA MALAT1 acted as a sponge of miR-125a to regulate IL-21R signaling, leading to gastric tumorigenicity (Fig. 7).

\section{Acknowledgements}

Not applicable.

\section{Funding}

The present study was supported by the Natural Science Foundation of Henan Province (Grant no. 162300410284).

\section{Availability of data and materials}

The datasets used and/or analyzed during the current study are available from the corresponding author on reasonable request.

\section{Authors' contributions}

LY and JZ contributed equally to this article. XWH designed this article and supervised its quality. LY wrote this paper and performed the experiments. JZ performed the experiments and revised the paper. DG and JM were responsible for collecting all the data, and SFS used the prediction tools and analyzed the data in the study. XWH and JZ checked the manuscript and all authors have read and approved the final manuscript.

\section{Ethics approval and consent to participate}

This study was approved by Medical Ethics Committee of Zhengzhou University, and written informed consent was obtained from the patients prior to sample collection. All experimental procedures were performed according to the regulations and internal biosafety and bioethics guidelines and the use of animals was approved by the Ethics Review Commission of Zhengzhou University.

\section{Patient consent for publication}

Not applicable.

\section{Competing interests}

The authors declare that they have no competing interests.

\section{References}

1. Hu XT and He C: Recent progress in the study of methylated tumor suppressor genes in gastric cancer. Chin J Cancer 32: 31-41, 2013

2. Yang XB, Zhao JJ, Huang CY, Wang QJ, Pan K, Wang DD, Pan QZ, Jiang SS, Lv L, Gao X, et al: Decreased expression of the FOXO3a gene is associated with poor prognosis in primary gastric adenocarcinoma patients. PLoS One 8: e78158, 2013.

3. Wogan GN, Hecht SS, Felton JS, Conney AH and Loeb LA: Environmental and chemical carcinogenesis. Semin Cancer Biol 14: 473-486, 2004.

4. Buffart TE, Tijssen M, El-Bchiri J, Duval A, van de Wiel MA, Ylstra B, Meijer GA and Carvalho B: NMD inhibition fails to identify tumour suppressor genes in microsatellite stable gastric cancer cell lines. BMC Med Genomics 2: 39, 2009.

5. Friday BB and Adjei AA: K-ras as a target for cancer therapy. Biochim Biophys Acta 1756: 127-144, 2005. 
6. Bah N, Maillet L, Ryan J, Dubreil S, Gautier F, Letai A, Juin P and Barillé-Nion S: Bcl-xL controls a switch between cell death modes during mitotic arrest. Cell Death Dis 5: e1291, 2014.

7. Yuan MJ and Wang T: Advances of the interleukin-21 signaling pathway in immunity and angiogenesis. Biomed Rep 5: 3-6, 2016.

8. Cha Z, Gu H, Guo H, Tu X, Zang Y, Zhao C, Hua M, Rechlic JR, Olasnova LM, Song $\mathrm{H}$, et al: Effect of interleukin 21 and its receptor on $\mathrm{CD}^{+} \mathrm{T}$ cells in the pathogenesis of diffuse large B-cell lymphoma. Oncol Lett 8: 421-425, 2014.

9. Browning RL, Mo X, Muthusamy N and Byrd JC: CpG oligodeoxynucleotide CpG-685 upregulates functional interleukin-21 receptor on chronic lymphocytic leukemia B cells through an NF- $\mathrm{kB}$ mediated pathway. Oncotarget 6: 15931-15939, 2015.

10. Wood B, Sikdar S, Choi SJ, Virk S, Alhejaily A, Baetz T and LeBrun DP: Abundant expression of interleukin-21 receptor in follicular lymphoma cells is associated with more aggressive disease. Leuk Lymphoma 54: 1212-1220, 2013.

11. Zhang M, Mathews Griner LA, Ju W, Duveau DY, Guha R, Petrus MN, Wen B, Maeda M, Shinn P, Ferrer M, et al: Selective targeting of JAK/STAT signaling is potentiated by Bcl-xL blockade in IL-2-dependent adult T-cell leukemia. Proc Natl Acad Sci USA 112: 12480-12485, 2015.

12. Hao Y, Chapuy B, Monti S, Sun HH, Rodig SJ and Shipp MA: Selective JAK2 inhibition specifically decreases Hodgkin lymphoma and mediastinal large B-cell lymphoma growth in vitro and in vivo. Clin Cancer Res 20: 2674-2683, 2014.

13. He L and Hannon GJ: MicroRNAs: Small RNAs with a big role in gene regulation. Nat Rev Genet 5: 522-531, 2004

14. Fang Z, Zhang L, Liao Q, Wang Y, Yu F, Feng M, Xiang X and Xiong J: Regulation of TRIM24 by miR-511 modulates cell proliferation in gastric cancer. J Exp Clin Cancer Res 36: 17 2017.

15. Ding L, Zhang S, Xu M, Zhang R, Sui $\mathrm{P}$ and Yang Q: MicroRNA-27a contributes to the malignant behavior of gastric cancer cells by directly targeting PH domain and leucine-rich repeat protein phosphatase 2. J Exp Clin Cancer Res 36: 45 2017.

16. Tang Y, Cui Y, Li Z, Jiao Z, Zhang Y, He Y, Chen G, Zhou Q, Wang W, Zhou X, et al: Radiation-induced miR-208a increases the proliferation and radioresistance by targeting $\mathrm{p} 21$ in human lung cancer cells. J Exp Clin Cancer Res 35: 7, 2016.

17. Yang R, Fu Y, Zeng Y, Xiang M, Yin Y, Li L, Xu H, Zhong J and Zeng X: Serum miR-20a is a promising biomarker for gastric cancer. Biomed Rep 6: 429-434, 2017

18. Imaoka H, Toiyama Y, Okigami M, Yasuda H, Saigusa S, Ohi M, Tanaka K, Inoue Y, Mohri Y and Kusunoki M: Circulating microRNA-203 predicts metastases, early recurrence, and poor prognosis in human gastric cancer. Gastric Cancer 19: 744-753, 2016.

19. Qu X, Zhou J, Wang T, Han J, Ma L, Yu H, Geng D, Fan H, Zhang Q, Hua F, et al: MiR-30a inhibits Th17 differentiation and demyelination of EAE mice by targeting the IL-21R. Brain Behav Immun 57: 193-199, 2016.

20. Yun S, Lee SU, Kim JM, Lee HJ, Song HY, Kim YK, Jung H, Park YJ, Yoon SR, Oh SR, et al: Integrated mRNA-microRNA profiling of human NK cell differentiation identifies MiR-583 as a negative regulator of IL2R $\gamma$ expression. PLoS One 9: e108913, 2014.

21. Wang Y, Wang K, Dang N, Wang L and Zhang M: Downregulation of miR-3940-5p promotes T-cell activity by targeting the cytokine receptor IL-2R gamma on human cutaneous T-cell lines. Immunobiology 221: 1378-1381, 2016.

22. Laneve P, Po A, Favia A, Legnini I, Alfano V, Rea J, Di Carlo V, Bevilacqua V, Miele E, Mastronuzzi A, et al: The long noncoding RNA linc-NeD125 controls the expression of medulloblastoma driver genes by microRNA sponge activity. Oncotarget 8 : 31003-31015, 2017

23. Shao Y, Ye M, Li Q, Sun W, Ye G, Zhang X, Yang Y, Xiao B and Guo J: LncRNA-RMRP promotes carcinogenesis by acting as a miR-206 sponge and is used as a novel biomarker for gastric cancer. Oncotarget 7: 37812-37824, 2016.

24. Zhang J, Wang G, Chu SJ, Zhu JS, Zhang R, Lu WW, Xia LQ, $\mathrm{Lu} \mathrm{YM}, \mathrm{Da}$ W and Sun Q: Loss of large tumor suppressor 1 promotes growth and metastasis of gastric cancer cells through upregulation of the YAP signaling. Oncotarget 7: 16180-16193, 2016.

25. Livak KJ and Schmittgen TD: Analysis of relative gene expression data using real-time quantitative PCR and the 2(-Delta Delta C(T)) method. Methods 25: 402-408, 2001
26. Cerami E, Gao J, Dogrusoz U, Gross BE, Sumer SO, Aksoy BA, Jacobsen A, Byrne CJ, Heuer ML, Larsson E, et al: The cBio cancer genomics portal: An open platform for exploring multidimensional cancer genomics data. Cancer Discov 2: 401-404, 2012.

27. Szász AM, Lánczky A, Nagy Á, Förster S, Hark K, Green JE, Boussioutas A, Busuttil R, Szabó A and Győrffy B: Cross-validation of survival associated biomarkers in gastric cancer using transcriptomic data of 1,065 patients. Oncotarget 7: 49322-49333, 2016.

28. Hu L, Wu Y, Tan D, Meng H, Wang K, Bai Y and Yang K Up-regulation of long noncoding RNA MALAT1 contributes to proliferation and metastasis in esophageal squamous cell carcinoma. J Exp Clin Cancer Res 34: 7, 2015.

29. Li Y, Wu Z, Yuan J, Sun L, Lin L, Huang N, Bin J, Liao Y and Liao W: Long non-coding RNA MALAT1 promotes gastric cancer tumorigenicity and metastasis by regulating vasculogenic mimicry and angiogenesis. Cancer Lett 395: 31-44, 2017.

30. Jadaliha M, Zong X, Malakar P, Ray T, Singh DK, Freier SM, Jensen T, Prasanth SG, Karni R, Ray PS, et al: Functional and prognostic significance of long non-coding RNA MALAT1 as a metastasis driver in ER negative lymph node negative breast cancer. Oncotarget 7: 40418-40436, 2016.

31. Deng QJ, Xie LQ and Li H: Overexpressed MALAT1 promotes invasion and metastasis of gastric cancer cells via increasing EGFL7 expression. Life Sci 157: 38-44, 2016.

32. Davis ID, Skak K, Smyth MJ, Kristjansen PE, Miller DM and Sivakumar PV: Interleukin-21 signaling: Functions in cancer and autoimmunity. Clin Cancer Res 13: 6926-6932, 2007.

33. Ueda M, Imada K, Imura A, Koga H, Hishizawa $M$ and Uchiyama T: Expression of functional interleukin-21 receptor on adult T-cell leukaemia cells. Br J Haematol 128: 169-176, 2005.

34. Bolzoni M, Ronchetti D, Storti P, Donofrio G, Marchica V, Costa F, Agnelli L, Toscani D, Vescovini R, Todoerti K, et al: IL21R expressing CD14+CD16+ monocytes expand in multiple myeloma patients leading to increased osteoclasts. Haematologica 102: 773-784, 2017.

35. de Totero D, Meazza R, Zupo S, Cutrona G, Matis S, Colombo M, Balleari E, Pierri I, Fabbi M, Capaia M, et al: Interleukin-21 receptor (IL-21R) is up-regulated by CD40 triggering and mediates proapoptotic signals in chronic lymphocytic leukemia B cells. Blood 107: 3708-3715, 2006.

36. Wang LN, Cui YX, Ruge F and Jiang WG: Interleukin 21 and its receptor play a role in proliferation, migration and invasion of breast cancer cells. Cancer Genomics Proteomics 12: 211-221, 2015.

37. Yin F, Zhang JN, Wang SW, Zhou CH, Zhao MM, Fan WH, Fan M and Liu S: MiR-125a-3p regulates glioma apoptosis and invasion by regulating Nrg1. PLoS One 10: e0116759, 2015.

38. Pan L, Zhou L, Yin W, Bai J and Liu R: miR-125a induces apoptosis, metabolism disorder and migrationimpairment in pancreatic cancer cells by targeting Mfn2-related mitochondrial fission. Int J Oncol 53: 124-136, 2018

39. Yan L, Yu MC, Gao GL, Liang HW, Zhou XY, Zhu ZT, Zhang CY, Wang YB and Chen X: MiR-125a-5p functions as a tumour suppressor in breast cancer by downregulating BAP1. J Cell Biochem: Aug 4, 2018 (Epub ahead of print) doi: 10.1002/jcb.27124.

40. Bayoumi AS, Sayed A, Broskova Z, Teoh JP, Wilson J, Su H, Tang YL and Kim IM: Crosstalk between Long Noncoding RNAs and MicroRNAs in Health and Disease. Int J Mol Sci 17: 356, 2016

41. Chen L, Yao H, Wang K and Liu X: Long non-coding RNA MALAT1 regulates ZEB1 expression by sponging miR-143-3p and promotes hepatocellular carcinoma progression. J Cell Biochem 118: 4836-4843, 2017.

42. Hou Z, Xu X, Zhou L, Fu X, Tao S, Zhou J, Tan D and Liu S: The long non-coding RNA MALAT1 promotes the migration and invasion of hepatocellular carcinoma by sponging miR-204 and releasing SIRT1. Tumour Biol 39: 1010428317718135, 2017.

43. Li Z, Xu C, Ding B, Gao M, Wei X and Ji N: Long non-coding RNA MALAT1 promotes proliferation and suppresses apoptosis of glioma cells through derepressing Rap1B by sponging miR-101. J Neurooncol 134: 19-28, 2017.

44. Jiang LT, Wan CH, Guo QH, Yang SJ, Wu JD and Cai J: Long noncoding RNA metastasis-associated lung adenocarcinoma transcript 1 (MALAT1) promotes renal cell carcinoma progression via sponging miRNA-429. Med Sci Monit 24: 1794-1801, 2018.

This work is licensed under a Creative Commons Attribution-NonCommercial-NoDerivatives 4.0 International (CC BY-NC-ND 4.0) License. 